\title{
Management of Carotid Carvenous Fistula in Ghana; Challenges and Opportunities
}

\author{
Ronald Awoonor-Williams ${ }^{1}$, Raphael Kofi Vowotor ${ }^{2}$, Frank Nketiah-Boakye ${ }^{2}$, \\ George Asafo Adjaye Frimpong3,4, Angelina Ampong5, Joseph Adjei Kwarteng5, \\ Pierre Kusi Aidoo Amankwah4, Michael Leat ${ }^{6}$
}

${ }^{1}$ General Surgery Unit, Directorate of Surgery, Komfo Anokye Teaching Hospital, Kumasi, Ghana

${ }^{2}$ Neurosurgery Unit, Directorate of Surgery, Komfo Anokye Teaching Hospital, Kumasi, Ghana

${ }^{3}$ Department of Radiology, School of Medical Sciences, College of Health Sciences, Kwame Nkrumah University of Science and Technology, Kumasi, Ghana

${ }^{4}$ Radiology Unit, Directorate of Diagnostics, Komfo Anokye Teaching Hospital, Kumasi, Ghana

${ }^{5}$ Directorate of Ophthamology, Komfo Anokye Teaching Hospital, Kumasi, Ghana

${ }^{6}$ Directorate of Trauma and Orthopaedics, Komfo Anokye Teaching Hospital, Kumasi, Ghana

Email: *vralph58@gmail.com

How to cite this paper: Awoonor-Williams, R., Vowotor, R.K., Nketiah-Boakye, F., Frimpong, G.A.A., Ampong, A., Kwarteng, J.A., Amankwah, P.K.A. and Leat, M. (2020) Management of Carotid Carvenous Fistula in Ghana; Challenges and Opportunities. Surgical Science, 11, 354-364. https://doi.org/10.4236/ss.2020.1111037

Received: June 30, 2020

Accepted: November 17, 2020

Published: November 20, 2020

Copyright $\odot 2020$ by author(s) and Scientific Research Publishing Inc. This work is licensed under the Creative Commons Attribution International License (CC BY 4.0).

http://creativecommons.org/licenses/by/4.0/

(c) (i) Open Access

\begin{abstract}
Carotid-cavernous fistula is an abnormal communication between the carotid artery and the cavernous sinus. The fistula is classified based on its etiology, haemodynamic and anatomical configuration. The most common type is the direct high flow fistula resulting from trauma. Indirect fistula which is less common results from underlying conditions such as hypertension, collagen vascular diseases, pregnancy amongst others. It is in regards with this uncommon occurrence of indirect fistula that we report a case of forty years old woman who presented with a left protruding eyeball and headache a month after delivery and was diagnosed with spontaneous type D indirect carotid cavernous fistula with rapidly progressing symptoms. She was referred abroad for interventional radiological services due to unavailability of such services in our facility and country.
\end{abstract}

\section{Keywords}

Carotid-Cavernous, Fistula, Direct, Indirect, Spontaneous, Pregnancy, Interventional and Radiological

\section{Introduction}

Carotid cavernous fistula (CCF) is an abnormal communication between two intracranial vascular structures namely: the carotid artery and the cavernous si- 
nus [1] [2]. Various configuration of the fistula can occur depending on which part is involved. The two main branches of the carotid artery or any of its branches can communicate with the cavernous sinus [3].

These fistulae are classified for the purpose of determining management modalities as well as prognosis. The classification takes into consideration the hemodynamic status, anatomical and etiological basis of the fistula [2].

The haeomdynamic nature of the fistula can be low or high flow. Anatomically, they are classified as direct or indirect and etiologically as spontaneous or traumatic [1] [2].

Direct carotid cavernous fistula occurs as a result of an abnormal communication between the internal carotid artery and the cavernous sinus. Indirect carotid cavernous fistula occurs between the meningeal branches of internal carotid artery and external carotid artery and the cavernous sinus [3] [4] [5].

On the basis of etiology, traumatic carotid cavernous fistulas are by far commoner than spontaneous accounting for about $75 \%$ of all cases [6]. Spontaneous carotid cavernous fistula is common in the elderly and female patients. They account for about a third of all carotid cavernous fistula [1] [7] [8] [9].

We report a case of spontaneous carotid cavernous fistula in a forty year-old postpartum female and the challenges in the management of the case.

\section{Case Report}

A forty year old woman was referred to the outpatient neurosurgical clinic from ophthalmology with a month's history of gradual protruding left eyeball and headache. She delivered via spontaneous vaginal delivery days prior to noticing the onset of the protrusion. The headache was hemi global on the left side, throbbing in nature with no relieving or aggravating factors. This had progressively worsened associated with pain and blurring of vision in the left eye.

There was no history of trauma prior to the onset of the protrusion. She had a history of pregnancy induced hypertension during the last month of the pregnancy. Post-delivery, the blood pressure dropped to normal range and was under monitoring at the postnatal clinic. The past medical history was negative for diabetes or any connective tissue disease.

Her first delivery was via spontaneous vaginal delivery with an uneventful puerperium with no history of hypertensive disorder. The second was via cesarean section on account prolonged second stage.

On examination she was fully conscious. Vision was $6 / 6(20 / 20)$ in the right eye, and 6/9 (20/30) in the left eye. Anterior segment examination of the right eye yielded normal findings. On examination of the left eye, there was proptosis of the left eyeball (Figure 1(a)), with chemosis of the conjunctiva (Figure 1(b)). Cornea was clear, anterior segment was quiet and deep, with no cells or flares, pupil was reactive, and the lens was clear. Examination of the fundus of both eyes yielded no abnormal findings. There was no ophthalmoplegia. Intraocular pressures were $16 \mathrm{mmHg}$ in the right eye, and $42 \mathrm{mmHg}$ (markedly raised) in the left eye. A bruit was auscultated over the left orbit. 
Her blood pressure was 150/90mmHg. All other neurological examination was essentially normal. She had no features of connective tissue disease.

Contrast enhanced CT scan that was done showed an enlarged left carotid sinus as well as ipsilateral superior ophthalmic vein and dilated left meningeal vessel in the left temporal fossa connecting to the left middle cerebral artery (Figures 2(a)-(c)), a type D carotid cavernous fistula. There was no evidence of subarachnoid haemorrhage.

Assessment by the ophthalmologist prior to referral abroad revealed her headaches and vision of the left eye worsened from 6/9 (20/30) to 6/18 (20/60) over a three week period from the time of diagnosis and development of ophthalmoplegia. The patient was counseled for digital subtraction angiogram with trans-arterial embolization and referred abroad for the service.

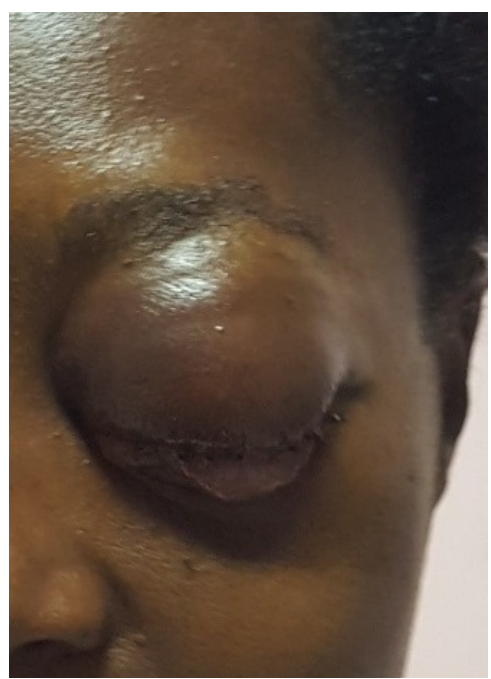

(a)

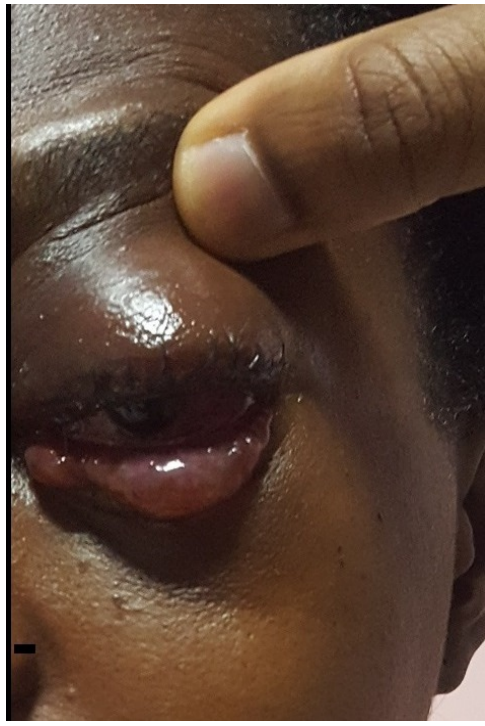

(b)

Figure 1. (a): showing proptosis of left eye ball; (b): showing chemosis of left conjunctiva. 


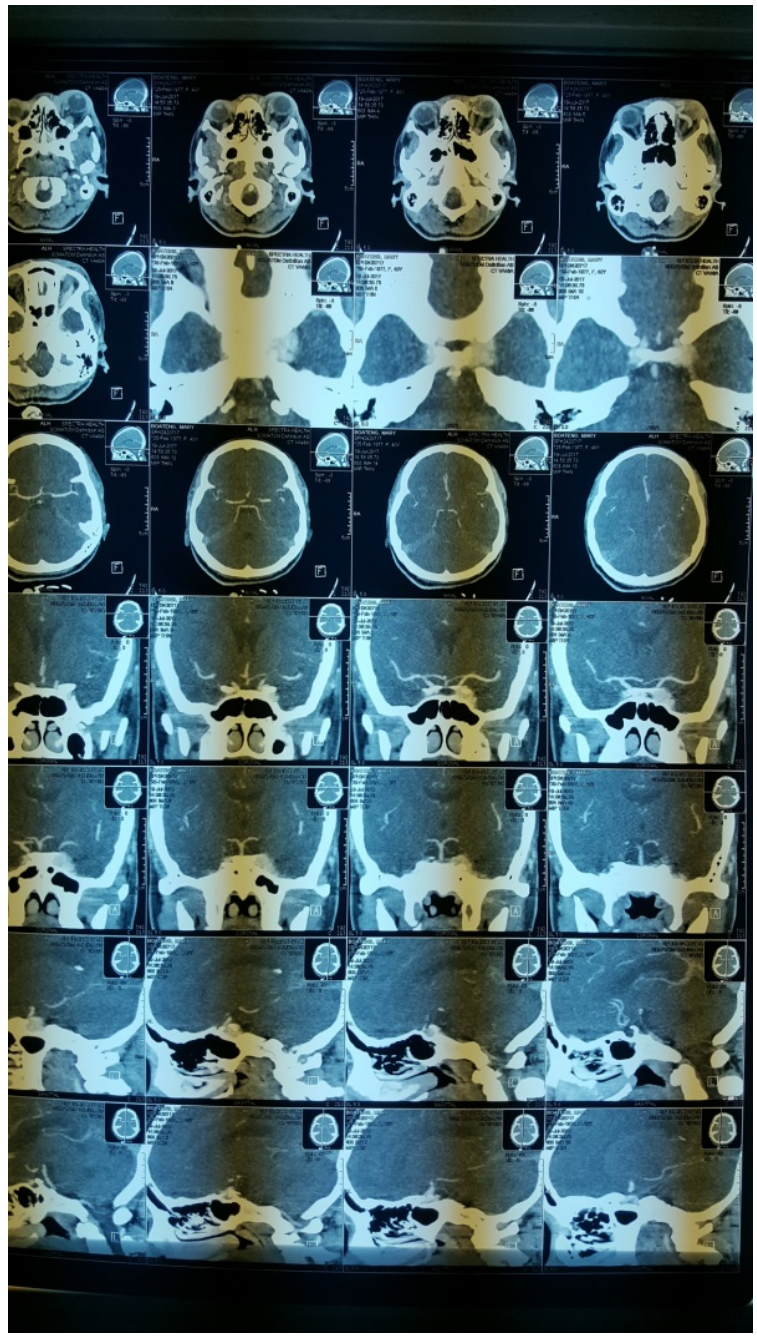

(a)

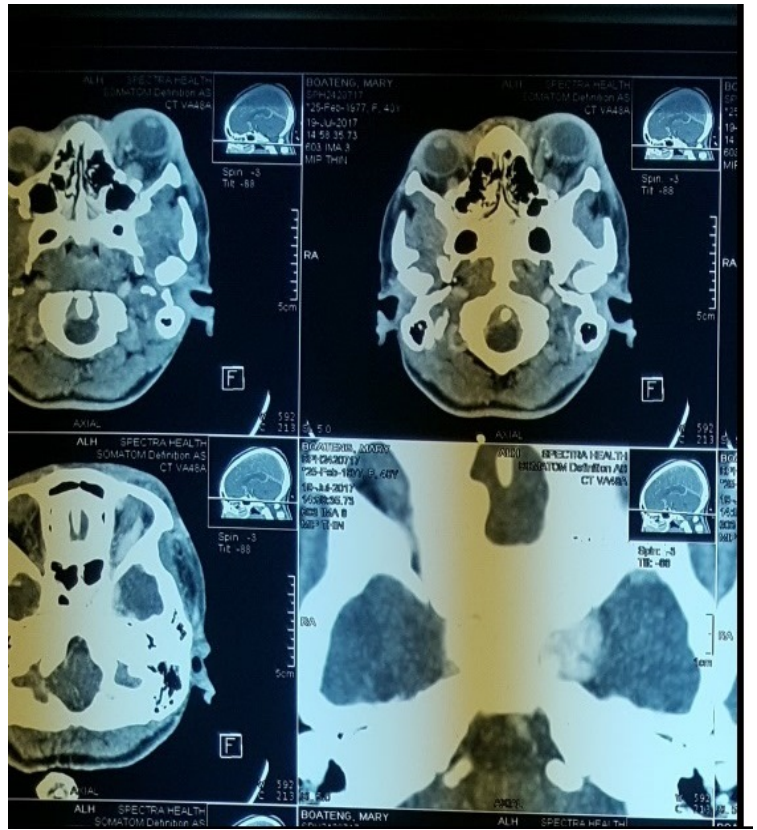

(b) 


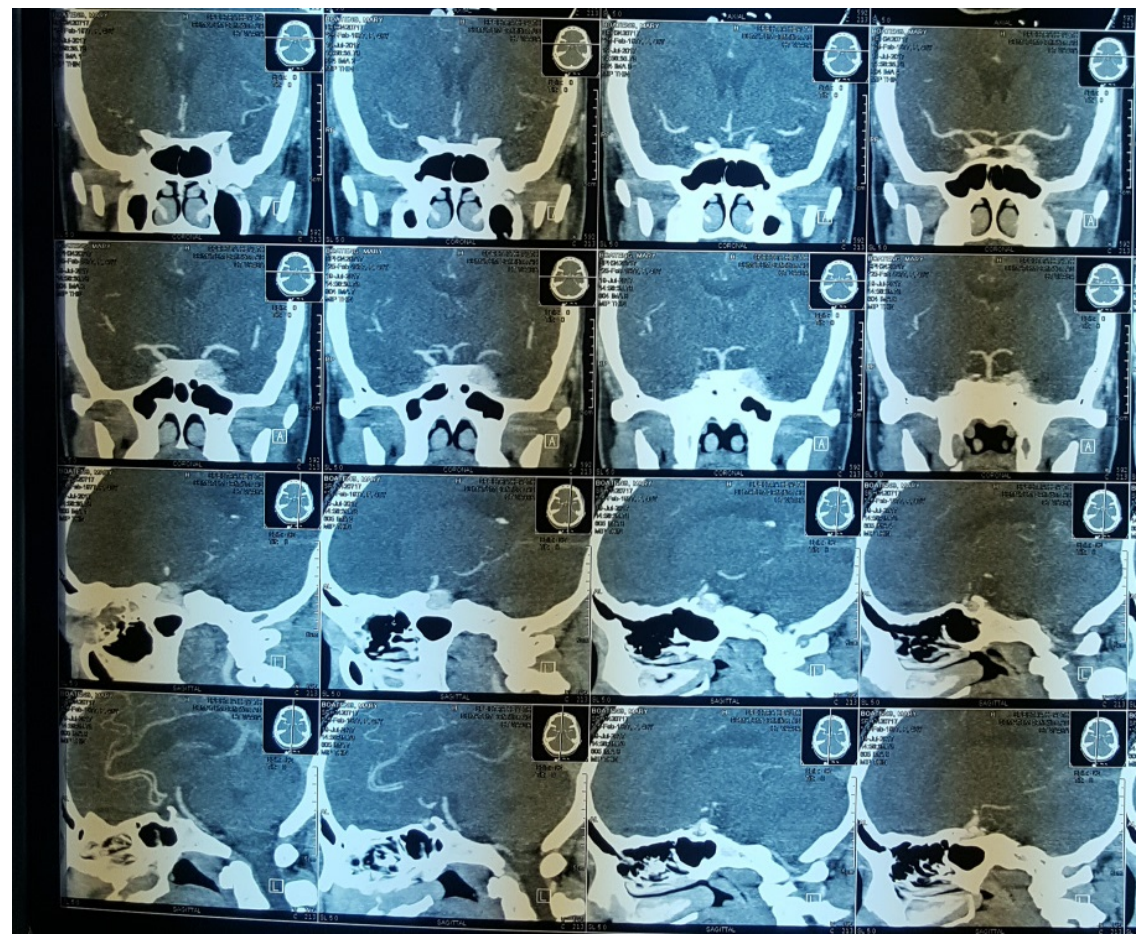

(c)

Figure 2. (a): Contrast enhanced CT scan of brain; (b): Axial view of CT scan showing proptosis of left eye ball parenchyma and vasculature; (c): Sagittal and coronal views of brain window showing left dilated cavernous sinus, as well as dilated left superior ophthalmic vein.

\section{Discussion}

Barrow et al. classifies carotid cavernous fistula (CCF) into four types, A to D. This anatomic classification provides essential information on the treatment options [1] [3].

Type A fistula is defined as a connection or communication between the intracavernous part of the internal carotid artery and the cavernous sinus. They are high flow in nature and are direct [2] [3]. Type B is an abnormal connection between meningeal branches of the internal carotid artery and the cavernous sinus [2] [3]. Type $C$ fistulae are abnormal connection between the meningeal or dural branches of the external carotid artery and the cavernous sinus [2] [3]. Type D occurs between the meningeal or dural branches of both the internal carotid artery and the external carotid artery and the carvenous sinus [1] [3].

Type A fistula is usually a high flow fistula which occurs as a result of trauma or iatrogenic injury [2] [3] [10].

Indirect fistula or dural fistula refers to dural or meningeal branches of the internal carotid artery and or the external carotid artery communicating with the cavernous sinus [1] [2] [3]. These fistulae; type B to D are usually low flow commonly seen in elderly women [3]. Predisposing factors to these types include systemic arterial hypertension, trauma, pregnancy, collagen vascular disease and artherosclerosis [10] [11] [12] [13] [14]. 
Aneurysmal dilatation of the cavernous portion of the internal carotid has been demonstrated as a major underlying condition predisposing to spontaneous fistula [15] [16] [17] [18]. Some connective diseases which predispose to weakening of the vascular wall with attendant risk of developing fistula in the presence of an appropriate precipitating factor such as coughing have been noted in the etiology of spontaneous CCF fistula [2] [3]. Conditions that predispose to spontaneous CCF include Ehlers Danlos syndrome, pseudoxanthoma elasticum, fibromuscular dysplasia. The predisposing factors have also been implicated in the spontaneous type A carotid cavernous fistula [19]-[24].

Another important pathophysiology is an increase in intracavernous sinus pressure resulting in damage of the delicate vessels of the cavernous sinus, in the presence of certain underlying conditions. Systemic arterial hypertension, artherosclerosis, pregnancy, diabetic vasculopathy and minor trauma may possibly be underlying causes [1] [6] [11] [14] [25] [26]. In pregnancy rise in blood pressure can lead to rupture of a preexisting aneurysmal dilatation and subsequently fistula formation [25]. In the index case, she had a history of pregnancy induced hypertension with no clinical features of connective tissue disease. Lin et al. and Toya et al. reported similar observations with CCF occurring in pregnancy [10] [14]. The history of pregnancy induced hypertension or straining during labour could have resulted in a rupture of a preexisting aneurysm. The anatomic configuration of her fistula was consistent with the presentation of that of a spontaneous indirect fistula. Walker and Allegre similarly reported of the occurrence of CCF during the latter half of pregnancy or delivery postulating that peripartum or pregnancy induced hypertension may lead to rupture of preexisting aneurysm [26].

Traumatic carotid cavernous fistula is the most common type accounting for about two thirds of cases [6]. Head injury associated with basal skull is a major cause and this is by far common in males. Vascular injury as a result of the direct tear from bony fragment or shear forces may lead to carotid cavernous fistula. Another mechanism is an increase intraluminal pressure in the internal carotid artery (ICA) with simultaneous distal compression leading to vascular tear [2] [27].

The management of CCF depends on the type, in combination with the nature of the flow, either high or low flow. The haemodynamic nature of the fistula which is helpful in understanding the clinical features and planning management is largely subject to bias. It is operator dependent [3]. The anatomic classification still serves as the key basis, since it can be objectively assessed. Nonetheless the haemodynamic nature is still used to help classify the fistula and determine management options and give an idea with respect to prognosis [1] [2] [3] [28].

\section{Clinical Presentation}

The clinical features depend on the site of the fistula, the extent of venous congestion and hypertension, the rate of flow and pressure gradient [2]. The features 
include proptosis, chemosis, diplopia, pain and visual loss [29] [30]. These were demonstrable in the index case. Bailey, Castro et al. and Toya et al. similarly described these clinical features in their cohort of patients with CCF [31] [32]. Kurata et al. also reported varying degrees of these clinical features demonstrable in the index case in the cohort of patients' studied [33]. The increased flow from the cavernous sinus into the orbital veins produces venous hypertension. This leads to oedema of the extraocular muscles manifesting as proptosis. The limited movement of the extraocular muscles as a result of oedema leads to diplopia [3]. The increased venous pressure results in impaired venous return of the conjunctiva presenting as chemosis [34].

Visual loss occurs as from decreased retinal blood flow due to stasis. Headache also occurs as a result retrograde cortical venous drainage. Pain is another symptom which occurs from possible involvement of the dural walls of the cavernous sinus in the direct type [3] [35].

Sudden onset of symptoms associated with audible bruit on auscultation is consistent with spontaneous CCF arising from ruptured aneurysmal dilatation [29]. The case under consideration on clinical examination had an audible bruit on auscultation. Both direct high flow and indirect low fistulae share similar clinical features [1] [2] [3] [35].

Complications are by far common in the high flow fistula. Loss of vision, intracerebral haemorrhage, subarachnoid haemorrhage, epistaxis, cranial nerve palsies are some of the reported complications [30] [36] [37]. Some of these complications are typified in the index case where she had cranial nerve palsies as well as worsening vision. Kurata et al. retrospective analysis on CCF indicated that cranial nerve palsy was more common in type D CCF [33].

There have been mixed reports about the progression and complications of the pathology. Toya et al. and Bailey reported complete resolution of symptoms in the patients whereas Castro et al. reported a rapid progression of symptoms similar to the index case [14] [31] [32].

\section{Radiological}

The radiological investigations that are beneficial in the diagnosis of this condition include; computed tomography (CT) scan, Magnetic resonance imaging (MRI) and cerebral CT angiogram [1] [2] [3] [28].

This delineates the characteristics of the fistula and identifies features including; proptosis, extra ocular muscle enlargement, superior ophthalmic vein dilatation, venous drainage patterns, flow pattern and associated injuries such as fractures. The gold standard is cerebral CT angiogram [1] [2] [3] [28].

In the index case the contrast enhanced was done to identify the anatomical configuration of the fistula. Bailey and Das et al. reported the use CT scan as a preliminary investigate tool later confirmed by MRI angiography [28] [31]. The standard angiography should be able to assess the common carotid and its bifurcation as well as the contralateral common carotid to exclude possible pseudo 
aneurysms, dissection or stenotic anatomy [3].

Management options for carotid cavernous fistula include open surgery and image guided interventions. The history of open surgery dates back as far as 1875 where the common carotid artery was ligated. However the success rate was low with high recurrence rate of the fistula. In the turn of the ninth century newer techniques to reduce the rate of recurrence have been described, all with various complications and recurrence rates [3].

Open surgical intervention still has role in the management of carotid cavernous fistula. The indications include; failure of trans-arterial or trans-venous endovascular intervention, and compromised proximal vascular access hindering endovascular approach [3].

Image guided intervention has become the mainstay of treatment. This form of intervention includes the trans arterial balloon occlusion technique and trans arterial coil occlusion technique largely for direct high flow Carotid-cavernous fistula. Indirect fistulae are managed via trans arterial or trans venous embolization techniques [3].

There are limited services for such an intervention within the sub region and for that matter the country [38]. Facilities for such service and human resource are desperately on the lower end with seemingly high burden of cases which require interventional radiological services to reduce morbidity and economic cost in the long term [38].

Training organizations within the sub region are yet to embark on this subspecialty within radiology [38].

The absence of facilities for such intervention in our setting is a limiting factor to the management of such cases necessitating referral abroad to patronize the service.

\section{Conclusion}

Carotid-cavernous fistula is an uncommon condition which requires the use of advances in interventional radiology for management. The paucity of personnel and the facilities for such services in developing country like Ghana with a high burden of cases requires a national and by extension, a regional strategy and commitment to improve availability in terms of access and affordability.

\section{Informed Consent}

Informed consent was obtained from the patient.

\section{Conflicts of Interest}

The authors declare no conflicts of interest regarding the publication of this paper.

\section{References}

[1] Barrow, L.D., Spector, H.R., Braun, F.I., Landman, J.A., Tindall, S.C. and Tindall, 
G.T. (1985) Classification and Treatment of Spontaneous Carotid-Cavernous Sinus Fistulas. Journal of Neurosurgery, 62, 248-256. https://doi.org/10.3171/jns.1985.62.2.0248

[2] Ellis, A.J., Goldstein, H., Sander Connolly Jr., E. and Meyers, M.P. (2012) Carotid-Cavernous Fistulas. Neurosurgical Focus, 32, 310-312. https://doi.org/10.3171/2012.2.FOCUS1223

[3] Ringer, A.J., Salud, L. and Tomsick, T.A. (2005) Carotid Cavernous Fistulas: Anatomy, Classification, and Treatment. Neurosurgery Clinics of North America, 16, 279-295. https://doi.org/10.1016/j.nec.2004.08.004

[4] Peeters, F.L.M. and Kroger, R. (1979) Dural and Direct Cavernous Fistulas. American Journal of Roentgenology, 132, 599-606. https://doi.org/10.2214/ajr.132.4.599

[5] Connors, J.J. and Wojak, J.C. (1999) Treatment of Carotid Cavernous Fistula. In: Interventional Neuroradiology: Strategies and Practical Techniques, WB Saunders, Philadelphia, 215-226.

[6] Yoo, K. and Krisht, A.F. (2000) Etiology and Classification of Cavernous Carotid Fistulas. In: Eisenberg, M.B. and Al-Mefty, O., Eds., The Cavernous Sinus. A Comprehensive Text, Lippincott Williams \& Wilkins, Philadelphia, 191-200.

[7] De Keizer, R. (2003) Carotid-Cavernous and Orbital Arteriovenous Fistulas: Ocular Features, Diagnostic and Hemodynamic Considerations in Relation to Visual Impairment and Morbidity. Orbit, 22, 121-142. https://doi.org/10.1076/orbi.22.2.121.14315

[8] Debrun, G.M., Viñuela, F., Fox, A.J., Davis, K.R. and Ahn, H.S. (1988) Indications for Treatment and Classification of 132 Carotid-Cavernous Fistulas. Neurosurgery, 22, 285-289. https://doi.org/10.1227/00006123-198802000-00001

[9] Viñuela, F., Fox, A.J., Debrun, G.M., Peerless, S.J. and Drake, C.G. (1984) Spontaneous Carotid-Cavernous Fistulas: Clinical, Radiological, and Therapeutic Considerations. Experience with 20 Cases. Journal of Neurosurgery, 60, 976-984. https://doi.org/10.3171/jns.1984.60.5.0976

[10] Lin, T.K., Chang, C.N. and Wai, Y.Y. (1992) Spontaneous Intracerebral Hematoma from Occult Carotid-Cavernous Fistula during Pregnancy and Puerperium. Case Report. Journal of Neurosurgery, 76, 714-717. https://doi.org/10.3171/jns.1992.76.4.0714

[11] Newton, T.H. and Hoyt, F.W. (1970) Dural Arteriovenous Shunts in the Region of the Cavernous Sinus. Neuroradiology, 1, 71-81. https://doi.org/10.1007/BF00389438

[12] Raskind, R., Johnson, N. and Hance, D. (1977) Carotid Cavernous Fistula in Pregnancy. Angiology, 28, 671-676. https://doi.org/10.1177/000331977702801002

[13] Slusher, M.M., Lennington, B.R., Weaver, R.G. and Davis Jr., C.H. (1979) Ophthalmic Findings in Dural Arteriovenous Shunts. Ophthalmology, 86, 720-731. https://doi.org/10.1016/S0161-6420(79)35454-9

[14] Toya, S., Shiobara, R., Izumi, J., Shinomiya, Y., Shiga, H. and Kimura, C. (1981) Spontaneous Carotid-Cavernous Fistula during Pregnancy or in the Postpartum Stage. Report of Two Cases Journal of Neurosurgery, 54, 252-256. https://doi.org/10.3171/jns.1981.54.2.0252

[15] Parkinson, D. (1967) Transcavernous Repair of a Carotid Cavernous Fistula: A Case Report. Journal of Neurosurgery, 26, 420-424. https://doi.org/10.3171/jns.1967.26.4.0420

[16] Kobayashi, N., Miyachi, S., Negoro, M., Suzuki, O., Hattori, K., Kojima, T. and Yoshida, J. (2003) Endovascular Treatment Strategy for Direct Carotid-Cavernous Fistulas Resulting from Rupture of Intracavernous Carotid Aneurysms. American 
Journal of Neuroradiology, 24, 1789-1796.

[17] Kupersmith, M.J., Stiebel-Kalish, H., Huna-Baron, R., Setton, A., Niimi, Y., Langer, D. and Berenstein, A. (2002) Cavernous Carotid Aneurysms Rarely Cause Subarachnoid Hemorrhage or Major Neurologic Morbidity. Journal of Stroke \& Cerebrovascular Diseases, 11, 9-14. https://doi.org/10.1053/jscd.2002.123969

[18] Linskey, M.E., Sekhar, L.N., Hirsch Jr., W., Yonas, H. and Horton, J.A. (1990) Aneurysms of the Intracavernous Carotid Artery: Clinical Presentation, Radiographic Features, and Pathogenesis. Neurosurgery, 26, 71-79.

https://doi.org/10.1227/00006123-199001000-00010

[19] Chuman, H., Trobe, J.D., Petty, E.M., Schwarze, U., Pepin, M., Byers, P.H. and Deveikis, J.P. (2002) Spontaneous Direct Carotid-Cavernous Fistula in Ehlers-Danlos Syndrome Type IV: Two Case Reports and a Review of the Literature. Journal of Neuro-Ophthalmology, 22, 75-81. https://doi.org/10.1097/00041327-200206000-00002

[20] Farley, M.K., Clark, R.D., Fallor, M.K., Geggel, H.S. and Hechkenlively, J.R. (1983) Spontaneous Carotid Cavernous Fistula and the Ehlers-Danlos Syndrome. Ophthalmology, 90, 1337-1342. https://doi.org/10.1016/S0161-6420(83)34384-0

[21] Numaguchi, Y., Higashida, R.T., Abernathy, J.M. and Pisarello, J.C. (1987) Balloon Embolization in Carotid Cavernous Fistula in Fibromuscular Dysplasia. American Journal of Neuroradiology, 8, 380-382.

[22] Taki, N., Nakahara, I., Nishi, S., Yamashita, K., Sadatou, A., Matsumoto, K., Tanaka, M. and Kikuchi, H. (1994) Pathogenic and Therapeutic Considerations of Carotid Cavernous Sinus Fistulas. Acta Neurochirurgica, 127, 6-14.

https://doi.org/10.1007/BF01808538

[23] Rios-Montenegro, E.N., Behrens, M.M. and Hoyt, W.F. (1972) Pseudoxanthoma Elasticum. Association with Bilateral Carotid Rete Mirabile and Unilateral Carotid-Cavernous Sinus Fistula. Archives of Neurology, 26, 151-155.

https://doi.org/10.1001/archneur.1972.00490080069007

[24] Hirai, T., Korogi, Y., Goto, K., Ogata, N., Sakamoto, Y. and Takahashi, M. (1996) Carotid-Cavernous Sinus Fistula and Aneurysmal Rupture Associated with Fibromuscular Dysplasia. A Case Report. Acta Radiologica, 37, 49-51. https://doi.org/10.1080/02841859609174358

[25] Taniguchi, R.M., Goree, J.A. and Odom, G.L. (1971) Spontaneous Carotid Cavernous Shunts Presenting Diagnostic Problems. Journal of Neurosurgery, 35, 384-391. https://doi.org/10.3171/jns.1971.35.4.0384

[26] Walker, A.E. and Allegre, G.E. (1956) Carotid-Cavernous Fistulas. Surgery, 39, 415-422.

[27] Helmke, K., Krüger, O. and Laas, R. (1994) The Direct Carotid Cavernous Fistula: A Clinical, Pathoanatomical, and Physical Study. Acta Neurochirurgica, 127, 1-5. https://doi.org/10.1007/BF01808537

[28] Van Rooij, W.J., Sluzewski, M. and Beute, G.N. (2006) Ruptured Cavernous Sinus Aneurysms Causing Carotid Cavernous Fistula: Incidence, Clinical Presentation, Treatment, and Outcome. American Journal of Neuroradiology, 27, 185-189.

[29] Das, J.K., Medhi, J., Bha, P., Borah, N., Bha, K., Kuri, G.C., Deka, H. and Goswami, B.J. (2007) Clinical Spectrum of Spontaneous Carotid-Cavernous Fistulas. Indian Journal of Ophthalmology, 32, 310-312. https://doi.org/10.4103/0301-4738.33051

[30] Tomsick, T.A. (1997) Types B, C, and D (Dural) CCF: Etiology, Prevalence, and Natural History. In: Carotid Cavernous Fistula, Digital Educational Publishing, Cincinnati, 59-73. 
[31] Bailey, C.R., Ray-Mazumder, N. and Manesh, R.S. (2016) Carotid Cavernous Fistula. Journal of General Internal Medicine, 32, 483-484. https://doi.org/10.1007/s11606-016-3860-6

[32] Castro, L.N.G., Colorado, R.A., Botelho, A.A., Freitag, S.K., Rabinov, J.D. and Silverman, S.B. (2016) Carotid-Cavernous Fistula A Rare But Treatable Cause of Rapidly Progressive Vision Loss. Stroke, 47, e207-e209. https://doi.org/10.1161/STROKEAHA.116.013428

[33] Kurata, A., Takano, M., Tokiwa, K., Miyasaka, Y., Yada, K. and Kan, S. (1993) Spontaneous Carotid Cavernous Fistula Presenting Only with Cranial Nerve Palsies. American Journal of Neuroradiology, 14, 1097-1101.

[34] Lasjaunas, P. and Berenstein, A. (1987) The Inferolateral Trunk. In: Surgical Neuroangiography, Springer-Verlag, New York, Vol. 1, 70-71.

[35] Grossman, R.I., Sergot, R.C. and Goldberg, H.I. (1985) Dural Malformations with Ophthalmic Manifestations: Results of Particulate Embolization in Seven Patients. American Journal of Neuroradiology, 6, 809-813.

[36] Huai, R.C., Yi, C.L., Ru, L.B., Chen, G.H., Guo, H.H. and Luo, L. (2008) Traumatic Carotid Cavernous Fistula Concomitant with Pseudoaneurysm in the Sphenoid Sinus. Interventional Neuroradiology, 14, 59-68. https://doi.org/10.1177/159101990801400108

[37] Lewis, A.I., Tomsick, T.A. and Tew Jr., J.M. (1995) Management of 100 Consecutive Direct Carotid-Cavernous Fistulas: Results of Treatment with Detachable Balloons. Neurosurgery, 36, 239-245. https://doi.org/10.1097/00006123-199502000-00001

[38] Sakodie, D.B. and Awuku, Y.A. (2017) Interventional Radiology Practice in Ghana: The Current and the Future. Postgraduate Medical Journal of Ghana, 6, 135-136. 